\title{
Review of Alex Sharpe's Sexual Intimacy and Gender Identity 'Fraud': Reframing the Legal and Ethical Debate (Routledge 2019; ISBN: 978-0-367-28024-6)
}

\section{Claire Hogg ${ }^{1}$}

Published online: 27 April 2020

(c) The Author(s) 2020

\begin{abstract}
In her newest book, Alex Sharpe makes a persuasive case against the bringing of sexual offence prosecutions on the basis of "gender identity fraud". Adopting a perspective in which queer and gender non-conforming identities are acknowledged and centred rather than doubted and dissected, Sharpe aims to destabilise the conceptual foundations upon which such prosecutions depend. In this review I place Sharpe's contribution in its legal context, and offer an overview of her argument along with some reservations.
\end{abstract}

Keywords Sexual offences · Rape by deception · Gender identity fraud · Queer theory $\cdot$ Book review

\section{Introduction}

In Sexual Intimacy and Gender Identity Fraud, Alex Sharpe offers a critical analysis of the emergence of gender identity fraud as a prominent subcategory of sexual fraud prosecutions. Adopting a queer approach (one which "takes as axiomatic the idea that sex, gender and sexuality are socially constructed" (7)), Sharpe aims to expose the ways in which the prevailing narrative surrounding these gender identity cases is tenable only within a strict hetero- and cis-normative framework, where categories of sex and gender are ontological truths to be revealed. In questioning the existence of an "ontological gap" between represented gender and "real" gender, Sharpe calls the conceptual coherence of gender identity fraud into question, forcing the reader to confront the cultural and social biases which implicitly shape our understanding of deception in a sexual context. In Sharpe's important and timely work, the current legal approach to gender identity fraud is revealed as one in which certain narratives

Claire Hogg

claire.hogg@kcl.ac.uk

1 King's College London, London, UK 
are inherently prioritised over others, to the detriment of those individuals who live their lives outside of the traditional categories of sex and gender.

The book has the air of a polemic, in which Sharpe calls urgently for an end to prosecutions brought on the basis of gender identity fraud. Part I involves a degree of scene-setting; Sharpe uses her first chapter to introduce "a series of interrelated themes"-ideology, agency, ignorance/knowledge, act/identity, resistance, law's bodily aesthetics, act/omission, consent, harm, and deception-to be developed over the course of the book. She then provides a brief account of the history of sexual fraud and the recent spate of gender identity cases, tracking their development from the early case of Saunders ${ }^{1}$ to the most recent decisions in Lee (Mason) ${ }^{2}$ and Staines. ${ }^{3}$ With this groundwork laid, the bulk of Sharpe's argument is developed in Part II. There is an impressive breadth to Sharpe's treatment, with the topic critiqued from a variety of angles. In Chapters 3 and 4 she sets out her case from the standpoint of legal principle, putting forth eight "principled objections" against prosecutions on the basis of gender identity fraud. ${ }^{4}$ Chapter 5 moves to interrogate matters of legal practice, with particular attention paid to the decision to prosecute in gender identity fraud cases, the tendency of defendants in such cases to enter a guilty plea, and the "unravelling" of the active deception/non-disclosure distinction in practice. Chapter 6 then addresses the ethical dimension of the debate, dealing in particular with the question of the moral obligation of trans and gender non-conforming individuals to self-disclose in a sexual context; a question which Sharpe "turns on its head" by rejecting the premise of a hidden truth to be disclosed. Sharpe concludes, finally, with a queer re-writing of 2012's McNally, in which she maps out an alternative interpretation of-and resolution to-this controversial case.

Sharpe's book represents the first significant, sustained exploration of gender identity fraud in the criminal law of England and Wales, an area in which hers has long been the most prominent critical voice. ${ }^{5}$ While heavily influenced

\footnotetext{
1 12/10/91, Unreported, Doncaster Crown Court, Judge Crabtree.

2 16/12/15, Unreported, Lincoln Crown Court, Judge Heath.

3 24/3/16, Unreported, Bristol Crown Court, Judge Cotter.

${ }^{4}$ These are: (1) that such prosecutions constitute "significant criminal law overreach"; (2) that the framing of sexual autonomy as "a non-negotiable right" is, perhaps counter-intuitively, detrimental to sexual agency; (3) that determinations as to fact materiality in the context of sexual fraud "produce legal inconsistency and are potentially discriminatory"; (4) that decisions to prosecute "fail to consider, or weigh properly, other rights and interests"; (5) that harm calculations used to justify criminalisation in gender identity fraud cases fail to give appropriate weight to the impact of such prosecutions on trans and gender non-conforming people; (6) that deception "is not a neutral category, but rather an effect of power"; (7) that the 'active'/'passive' deception distinction "lacks a principled basis"; and (8) that gender identity fraud prosecution "undermines important public policy interests", specifically "the liberal state's commitment to $[\ldots]$ its equality and diversity obligations, which include the amelioration of transphobia" (pp. 59-60, 85-86).

${ }^{5}$ See e.g. Alex Sharpe, "Queering Judgment: The Case of Gender Identity Fraud", 81(5) The Journal of Criminal Law (2017); Alex Sharpe, "The Ethicality of the Demand for (Trans)parency in Sexual Relations", 43(2) Australian Feminist Law Journal (2017); Alex Sharpe, "Expanding Liability for Sexual Fraud through the Concept of 'Active Deception': A Flawed Approach", 80(1) The Journal of Criminal Law (2016); Alex Sharpe, "Sexual Intimacy, Gender Variance, and Criminal Law", 33(4) Nordic Journal of Human Rights (2015); Alex Sharpe, "Criminalising Sexual Intimacy: Transgender Defendants and the Legal Construction of Non-Consent”, Criminal Law Review (2014).
} 
by post-structuralist thought, Sharpe is careful to counteract assumptions that her approach will prioritise "the conceptual [...] at the expense of the normative in mapping out jurisprudential space"; her book, she clarifies, "is explicitly concerned to express normative commitments and to make normative arguments" (7). It is clear from the outset that the book is written with a concrete goal in mind: to address the "urgent" legal situation currently facing trans and gender non-conforming individuals, and to point the way towards positive material change. Accordingly, Sharpe expresses a practical willingness to look within current legal structures for a solution to the problems she identifies, culminating in a final chapter in which she presents her queer alternative to the McNally judgement. Her book should, as such, appeal not only to readers who specialise in post-structuralist legal analysis, but to any legal theorist or practitioner with an interest in understanding the more complex dimensions of this emerging area of criminal law.

\section{Contextualising Sharpe: The Legal Background}

To understand the place and significance of Sharpe's contribution, a brief overview of the legal background may be helpful (a more comprehensive treatment is provided by Sharpe herself in the opening chapter). While the courts have long acknowledged coercion as anathema to valid consent, ${ }^{6}$ their position with respect to deception has typically been more cautious. Traditionally, the potential for deception to be regarded as consent-vitiating was restricted to two specific scenarios: Firstly, where the complainant was deceived by the defendant into believing that the sexual act performed upon her was not sexual in nature, ${ }^{7}$ and secondly where the complainant was deceived into believing that the defendant, to whom she was not married, was her husband. ${ }^{8}$ Outside of these very particular exceptions, a defendant's having been deceived as to certain facts was seen as incapable of invalidating consent which was otherwise freely given, no matter how material those facts may have been to a complainant's decision to give it.

In more recent years, however, the doctrine of sexual fraud or 'rape-by-deception' has been subject to significant development. In the late $20^{\text {th }}$ and early $21^{\text {st }}$ centuries a series of common law decisions saw the doctrine modestly expanded, with the scope of the two sexual fraud scenarios altered to reflect a less antiquated mindset. ${ }^{9}$ The real sea-change, however, came with the passing of the Sexual Offences Act 2003 (SOA). Rather than consolidating the previous common law rule against prosecution in sexual fraud cases, s.74 of the new legislation provided a statutory definition of consent broad enough to permit, at least in theory, its vitiation through deception. ${ }^{10}$

\footnotetext{
6 See: $R v$ Olugboja [1982] QB 320.

7 See: $R$ v Flattery [1877] 2 QBD 41; $R v$ Williams [1923] 1 KB 340.

${ }^{8}$ For discussion on the probable historical rationale behind these exceptions see Jed Rubenfeld, "The Riddle of Rape-by-Deception and the Myth of Sexual Autonomy”, 122 Yale L.J, (2013), pp. 1395-1403.

9 See: $R$ v Elbekkay [1995] Crim LP 163; $R$ v Devonald [2008] EWCA Crim 527.

10 Subject to judicial interpretation of the meaning of "freedom" in the context of sexual choice. That deception not amounting to one of the conclusive presumptions could nonetheless be capable of render-
} 
Meanwhile, the two traditional sexual fraud scenarios-formerly exceptions to that general common law rule-were transformed under s.76 into grounds for a conclusive presumption against the presence of consent. With these developments, the legal landscape fundamentally shifted. No longer was expansion of the doctrine of sexual fraud restricted to interpretation of the two traditional exceptional scenarios. Post-SOA, a claim of deception as consent-vitiating could be brought on the basis of the definition of consent as provided by s.74-and the potential for expansion through this avenue was, theoretically, limitless.

Subsequent decisions have made it clear, however, that not all deception is to be regarded as equal. In practice, expansion of the sexual fraud doctrine post-SOA has heavily concentrated on a particular class of cases; namely those in which the deception concerns the defendant's biological sex. ${ }^{11}$ The result of this focused development has been the emergence of gender identity fraud as a distinct subcategory of sexual fraud prosecutions, and it is this subcategory with which Sharpe is concerned. Drawing the boundaries of her investigation, Sharpe identifies this emerging class of prosecutions as typified not only by the subject of the alleged deception (the defendant's biological sex), but also by certain features which differentiate them from the broader category of sexual fraud cases (36). Firstly, they involve no coercion; the sexual act was unquestionably desired by the complainant at the time and only came to be regarded as undesirable retrospectively, once the deception was revealed. ${ }^{12}$ Secondly, they involve no breach on the defendant's part of any explicitly agreed upon condition. ${ }^{13}$ Thirdly, Sharpe identifies that in all such cases so far prosecuted the defendants have been young, gender non-conforming individuals designated female at birth, while the complainants have been young women (30). Finally and relatedly, these cases involve a genuine question as to the defendant's gender identity, whether or not this is acknowledged by the courts. ${ }^{14}$

Footnote 10 (continued)

ing a sexual choice unfree for the purposes of s.74 was confirmed in $R v$ Jheeta [2007] EWCA Crim 1699.

11 See: $R$ v Saunders 12/10/91; $R$ v Barker 5/3/12 (Unreported, Guildford Crown Court, Judge Moss); $R v$ McNally [2013] EWCA Crim 1051; $R v$ Wilson 7/3/13 (Unreported, Edinburgh High Court, Lord Bannatyne); $R$ v Newland 15/9/15 (Unreported, Chester Crown Court, Judge Dutton); $R v$ Lee (Mason) $16 / 12 / 15 ; R v$ Staines 24/3/16.

12 Contrast: $R v$ Jheeta [2007] (in which the defendant sent texts purporting to be from the police instructing the complainant to have sex with the defendant or be subject to a fine); $R v$ Bingham [2013] 2 Cr App R 29 (in which the defendant created false identities on a social media website to obtain explicit photographs of the complainant which he then used to blackmail her into sex).

13 Contrast: Assange v Swedish Prosecution Authority [2011] EWHC 2849 (in which consent had been conditional on condom use; failure to use a condom therefore vitiated consent); $R(F) v D P P$ [2013] EWHC 945 (in which consent had been conditional on the husband's agreement not to ejaculate inside his wife; his subsequent ejaculation therefore vitiated consent).

14 Contrast: $R v$ Devonald [2008] (in which the male defendant posed as a young woman online to seduce the complainant and induce him to masturbate on a webcam in order to humiliate him as revenge for mistreating his (the defendant's) daughter. As Sharpe observes, the deception in this case, though relating to the defendant's sex, was quite clearly divorced from questions of gender identity and presentation). 
The exemplar for such cases is 2012's McNally, ${ }^{15}$ a case which is appropriately given prominence in Sharpe's book. The facts of McNally, as understood by the Court of Appeal, were as follows: the defendant was a young woman who had pretended to be a boy, and in that guise had entered into a sexual relationship with the female complainant. Upon discovering that the defendant was "really [...] a girl" the complainant was "devastated" and "felt physically sick". ${ }^{16}$ Plainly a deception had occurred, the nature of which was quite clear. The issues to be decided were i) whether a deception of this nature was capable of being regarded as having vitiated consent; ii) whether the deception in question was "active"; and iii) whether the facts as to which the complainant was deceived were "material". Answering all three questions in the affirmative, the court convicted McNally. The possibility of "confusion surrounding [the defendant's] gender identity" was raised only in the context of sentencing. ${ }^{17}$ There was no mention of the word transgender, or any equivalent term, at any point in the judgement. A series of similar convictions relating to transgender or gender non-conforming defendants followed: $R v$ Wilson, ${ }^{18} R v$ Lee (Mason), and $R v$ Staines. ${ }^{19}$ All three cases were unreported, but mainstream newspaper coverage reflected the same narrative adopted by the court in McNally. Reporting on the case of Kyran Lee, a transgender man who had identified as male since adolescence and was, at the time of trial, awaiting gender reassignment surgery, The Telegraph ran the headline: "Woman posed as a single father to con Facebook friend into sex". 20 On the same case, remarking on sentencing, The Guardian announced: "Woman who used fake penis to have sex with a woman avoids jail". ${ }^{21}$

\section{Sharpe's Contribution}

Against this background Sharpe's analysis, in which queer and gender non-conforming identities are acknowledged and centered, provides a much-needed counterpoint. By examining McNally through the lens of queer theory, Sharpe is able to shift the perspective on this and other such cases, making explicit the cultural and ideological assumptions underwriting the decisions reached. Her position is that the conceptual coherence of gender identity fraud relies on the foundational premise that the categories of sex and gender are ontological truths which may be uncovered and

\footnotetext{
15 [2013] EWCA Crim 1051.

16 Ibid, at 10 .

17 Ibid, at 47: "The pre-sentence report spoke of a history of self-harm and confusion surrounding her gender identity and sexuality, which were resolving.".

18 7/3/13, Unreported, Edinburgh High Court, Lord Bannatyne.

19 Sharpe refers also to $R v$ Newland-although this case is rather more complex in that the defendant did not identify as male either at the time of the act or subsequently; her defence was rather that she and the complainant were involved in consensual gender-based sexual roleplay.

20 The Telegraph, 28 Oct 2015, accessed September 2019 https:/www.telegraph.co.uk/news/uknews/ law-and-order/11959495/Woman-posed-as-a-single-father-to-con-Facebook-friend-into-sex.html.

21 The Guardian, 15 Dec 2015, accessed September 2019 https://www.theguardian.com/uk-news/2015/ dec/15/woman-who-used-fake-penis-to-have-sex-with-a-woman-avoids-jail.
} 
compared to a defendant's self-representation; if Justine McNally's gender presentation is conceived not as pretense but as a genuine expression of male identity, ${ }^{22}$ then there is no deception for which to answer. In framing McNally's self-representation as a deception, therefore, the court both assumes and reinforces "the naturalness and stability of the categories of sex, gender and heterosexuality" (7). To exist outside of such categorisation becomes an inherently deceptive act, creating a situation in which "fixed identities are legally required":

[A] defendant either is the man or woman s/he claims to be (and therefore is not legally deceptive) or s/he is not (and therefore is legally deceptive). In other words, the possibility of being both or moving between categories is both precluded and taken as proof of deception. (6)

In this context, the distinction between active deception and non-disclosure seems doomed to break down, a point to which Sharpe regularly returns. If categories of sex and gender are regarded by the courts as fixed and unchanging, then any representation of gender incongruent with one's biological sex is potentially construable as active deception. Within these legal parameters, it seems, to live one's life as a man when one is biologically female is necessarily to deceive; the only way out of this bind is disclosure. As such, Sharpe explains, the current legal situation both reflects and reinforces (1) the view of trans and gender nonconforming people as "quintessentially deceptive", a myth she describes as "the most antithetical to the liveability of transgender lives" (133), and (2) the belief that trans and gender non-conforming people have an obligation to disclose their personal gender and bodily histories, at their expense of their privacy and personal safety. This focus on the material impact of the current legal approach not only upon those individuals targeted for prosecution, but on trans and gender nonconforming people in a broader sense, is a particular strength of Sharpe's treatment. There is a tendency among some proponents of an informed consent model to downplay, intentionally or otherwise, the harmful effects of legally required disclosure in a sexual context. In "Mistaken Sex", ${ }^{23}$ Jonathan Herring acknowledges that his proposed model ${ }^{24}$ may constitute an imposition on the right to privacy of trans and gender non-conforming individuals. ${ }^{25} \mathrm{He}$ argues, however, that this right is outweighed by the right of their partner to sexual autonomy-a right which can only be exercised when all material facts ${ }^{26}$ are known. What Sharpe's

\footnotetext{
22 There is reason to believe that McNally identified as male at the time of the offence, although she currently does not.

23 Jonathan Herring, "Mistaken Sex", 511 Crim LR (2005).

24 This model, in Herring's words, is as follows: "If at the time of the sexual activity a person (1) is mistaken as to a fact; and (2) had s/he known the truth about that fact would not have consented to it, then s/ he did not consent to the sexual activity. If the defendant knows (or ought to know) that s/he did not consent (in the sense just described) then s/he is guilty of an offence." (Herring (2005), p. 8).

25 Along with anyone else in possession of a trait or characteristic they might reasonably expect to be material to their sexual partner.

${ }^{26}$ For Herring, all that is required for a fact to be material is that the complainant happens to regard it as such. (Herring (2005) p. 8).
} 
discussion makes clear is that the harm of required disclosure, in the sexual context, of an individual's gender history extends far beyond an imposition on privacy. As Sharpe stresses, any harm balancing exercise must factor in, at minimum, the significant risks of such disclosure to an individual's physical safety (87-88), as well as the widespread material and psychological effects of a legal framework which validates the perception of trans identities as both inherently deceptive and inherently undesirable (86-89).

Though one must, I think, accept the overall force of Sharpe's argument, some of its aspects are stronger than others. In particular, her treatment of sexual autonomy (or "agency", as is her preferred term (63)) is given somewhat less development than it deserves, transforming fairly quickly into a discussion of fact materiality vis-à-vis the meaning of informed consent (62-68). Sharpe's position is that on any normative determination, facts as to gender identity ought not to be regarded as material to the question of whether consent was autonomously given. Her argument for this is twofold: firstly, she posits that once the ontological gap between "real" and presented gender is rejected, it becomes impossible to claim a violation of sexual autonomy on the basis of non-disclosure; "[C]laims of encroachment on a right to sexual autonomy only make sense in the present context $[\ldots]$ in circumstances where a gap exists between complainant belief about the defendant's gender identity and his actual gender identity" (65). Secondly, she argues that the disgust or horror which is frequently stated to motivate complainants' retrospective disavowals of desire may, in reality, be a response not to the actual transgender defendant as a sexual partner per se, but rather to the realisation that one is capable of experiencing sexual attraction to transgender people (66-68). These strike me as weak points in the book's overall argument. Certainly, Sharpe's hypothesis as to the nature of the discomfort expressed by complainants in gender identity fraud cases is both psychologically interesting and plausible. However, in the absence of a robust analysis of the relationship between knowledge and consent it is unclear why, or indeed whether, the precise nature of a complainant's discomfort post-disclosure ought to be regarded as relevant to the validity or invalidity of consent given prior. Similarly, while Sharpe's point about the ontological gap is certainly well taken, I think it is fair to say that these gender identity cases involve at least the non-disclosure of at least some facts, and so long as this much is granted then a degree of direct engagement with the broader question of the relationship between knowledge, consent and autonomy does seem warranted. Sharpe's limited engagement with this dimension of the rape-by-deception debate reflects a tendency to elide the fundamental matter at its heart, that is: whether an absence of information is capable of vitiating consent under any circumstances and, if so, which circumstances these are. Her preferred approach with respect to gender identity cases is to challenge the presumption that there exists, in any meaningful sense, an absence of information to be accounted for-a line that is persuasive, but only up to a point.

These reservations aside, Sharpe's work represents a significant and much needed contribution to the literature of sexual offences. Whether or not one is ultimately persuaded by her argument, Sharpe provides a perspective which has frequently been overlooked by the courts, but which must be engaged with in 
order to fully understand the implications of gender identity fraud as an emerging category of sexual fraud.

\section{Compliance with ethical standards}

Conflict of interest The author declares that he/she has no conflict of interest.

Open Access This article is licensed under a Creative Commons Attribution 4.0 International License, which permits use, sharing, adaptation, distribution and reproduction in any medium or format, as long as you give appropriate credit to the original author(s) and the source, provide a link to the Creative Commons licence, and indicate if changes were made. The images or other third party material in this article are included in the article's Creative Commons licence, unless indicated otherwise in a credit line to the material. If material is not included in the article's Creative Commons licence and your intended use is not permitted by statutory regulation or exceeds the permitted use, you will need to obtain permission directly from the copyright holder. To view a copy of this licence, visit http://creativecommons.org/licen ses/by/4.0/.

Publisher's Note Springer Nature remains neutral with regard to jurisdictional claims in published maps and institutional affiliations. 